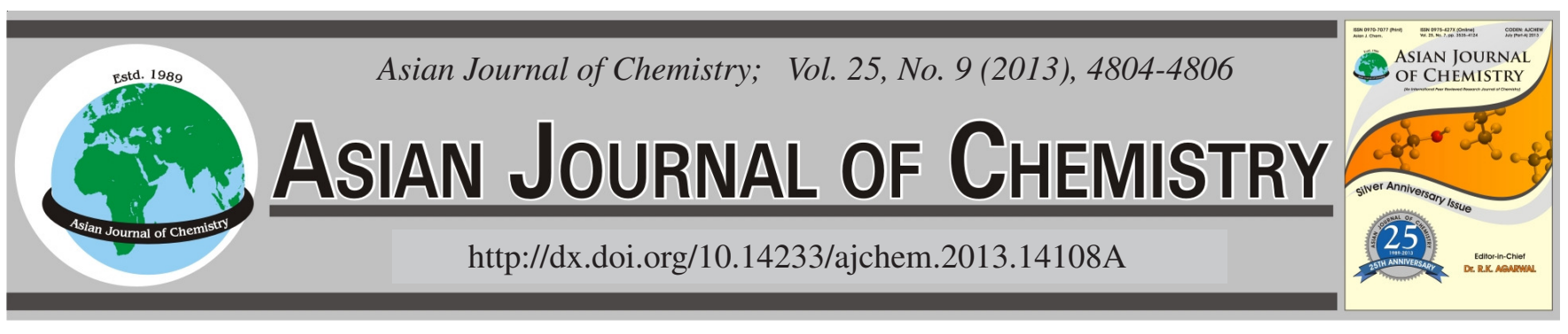

\title{
Effective Permittivity of DMSO + NaCl Aqueous \\ Solution as Influenced by Concentration and Temperature
}

\author{
Hai-Chuan Chen ${ }^{1,2}$, XiaO-Qing Yang ${ }^{1}$ and Ka Ma Huang ${ }^{1, *}$
}

${ }^{1}$ College of Electronics and Information Engineering, Sichuan University, Chengdu 610064, P.R. China

${ }^{2}$ College of Electrical Engineering and Information Technology, Xihua University, Chengdu 610039, P.R. China

*Corresponding author: E-mail: mailhai@126.com

(Received: 25 May 2012;

Accepted: 8 March 2013)

AJC-13076

\begin{abstract}
Dielectric properties of DMSO+NaCl aqueous solution were measured at the selected microwave frequency range $(2.45$ and $5.8 \mathrm{GHz})$ by the open-ended coaxial probe method using a network analyzer. The effects of temperature (293-353K) and concentration ( $0.1-0.5 \mathrm{~mol} / \mathrm{L})$ on dielectric properties were investigated. Temperature and concentration significantly contributed on dielectric characteristics of DMSO dispersion and ion exhibited the electric conductivity dispersion effect.
\end{abstract}

Key Words: Permittivity, DMSO, NaCl, Dielectric property.

\section{INTRODUCTION}

The solvent mixtures of water and dimethyl sulphoxide (DMSO) have special importance because of their unique physical and chemical ${ }^{1,2}$ properties. With respect to the chemical properties, the formation of water-DMSO mixtures is exothermic with the magnitude of the heat of mixing showing a strong negative ${ }^{3}$ deviation from ideality. Such as density, viscosity, refractive index ${ }^{4-6}$ permittivity and surface tension show positive deviations from ideality. The solvation of sodium chloride and other electrolytes in several one component solvents has been a subject of detailed investigations, both theoretically and through simulations, for a considerably long time. Molecular dynamical simulation studies on $\mathrm{NaCl}$ in the presence of model ${ }^{7-9}$ polar solvents, water, methanol and $\mathrm{DMSO}^{10}$ have been reported.

To our best of knowledge, dielectric study for this most ${ }^{11}$ commonly used electrolyte $(\mathrm{NaCl})$ has not been reported in mixed solvents such as water-DMSO. The objectives of the present work were to study the dielectric properties of three solutions of $\mathrm{NaCl}$ in mixtures of water and DMSO as a function of temperature and concentration. The information on dielectric properties of DMSO $\mathrm{NaCl}$ aqueous solution would be helpful to process industries to develop DMSO based polar solvents using microwave technology.

\section{EXPERIMENTAL}

DMSO (99.5 \%) and $\mathrm{NaCl}(99.5 \%)$ were purchased from the Chengdu Kelong Chemical Factory. A vector network analyzer Agilent N5230A, with an Agilent open-ended coaxial cable connected to a Agilent $85070 \mathrm{E}$ dielectric probe was employed to measure dielectric properties of $\mathrm{DMSO}+\mathrm{NaCl}$ aqueous solution. The instrument was calibrated by measuring the properties of air, short-circuit block and water at $293 \mathrm{~K}$. The instrument was turned on at least $2 \mathrm{~h}$ before the calibration to obtain precise results and measurements were made. The sample ( $c a .40 \mathrm{~mL})$ was placed in a wide glass tube $(50 \mathrm{~mL})$ and the open coaxial probe (probe diameter $\approx 20 \mathrm{~mm}$ ) was inserted into the tube. The sample holder was dipped into a temperature controlled water bath with agitation. The network analyzer probe and the cable were fixed together so that there could be no movement during sample measurement and data acquisition. The sample was heated from 293-363 K and dielectric properties were measured while samples achieved the required temperatures (293-353 K). A temperature controller system with a water bath and thermostat was used to maintain the temperature constant within $\pm 0.5 \mathrm{~K}$. The sample cell was surrounded by a heat insulating container through which the constant temperature water was circulated. The temperature at the cell was checked using a thermometer sensor. (dielectric constant $\varepsilon^{\prime}$ and dielectric loss factor $\varepsilon^{\prime \prime}$ were automatically computed and recorded with the manufacturer supplied computer software. All the measurements were carried out in triplicate and were reproducible to $\pm 5 \%$. Mean values and standard errors were calculated from three replicates.

\section{RESULTS AND DISCUSSION}

The experiment effective permittivity data are listed in Tables 1 and 2. It has been observed that dielectric constant $\varepsilon^{\prime}$ 


\begin{tabular}{|c|c|c|c|c|c|c|c|c|c|c|c|c|c|}
\hline \multicolumn{14}{|c|}{$\begin{array}{r}\text { TABLE-1 } \\
\text { REAL AND IMAGINARY PARTS OF THE EFFECTIVE }\end{array}$} \\
\hline \multirow{2}{*}{\multicolumn{2}{|c|}{$2.45 \mathrm{G}$}} & \multicolumn{2}{|c|}{$293 \mathrm{~K}$} & \multicolumn{2}{|c|}{$298 \mathrm{~K}$} & \multicolumn{2}{|c|}{$308 \mathrm{~K}$} & \multicolumn{2}{|c|}{$318 \mathrm{~K}$} & \multicolumn{2}{|c|}{$338 \mathrm{~K}$} & \multicolumn{2}{|c|}{$353 \mathrm{~K}$} \\
\hline & & $\varepsilon^{\prime}$ & $\varepsilon^{\prime \prime}$ & $\varepsilon^{\prime}$ & $\varepsilon^{\prime \prime}$ & $\varepsilon^{\prime}$ & $\varepsilon^{\prime \prime}$ & $\varepsilon^{\prime}$ & $\varepsilon^{\prime \prime}$ & $\varepsilon^{\prime}$ & $\varepsilon^{\prime \prime}$ & $\varepsilon^{\prime}$ & $\varepsilon "$ \\
\hline $\mathrm{X}(\mathrm{NaCl})$ & $\mathrm{x}$ (DMSO) & \pm 3.5 & \pm 1.2 & \pm 3.5 & \pm 1.2 & \pm 3.4 & \pm 1.2 & \pm 3.3 & \pm 1.2 & \pm 3.5 & \pm 1.2 & \pm 3.2 & \pm 1.3 \\
\hline 0 & 0 & 78.99 & 10.7 & 77.23 & 9.15 & 73.77 & 6.49 & 70.65 & 4.88 & 65.81 & 3.59 & 61.52 & 2.53 \\
\hline 0.1 & 0.33 & 22.26 & 19.64 & 20.13 & 16.33 & 35.9 & 25.6 & 50.79 & 22.26 & 47.97 & 16.96 & 38.83 & 15.76 \\
\hline 0.1 & 0.50 & 23.93 & 17.76 & 20.48 & 14.84 & 35.72 & 22.39 & 48.21 & 20.16 & 47.13 & 15.85 & 34.62 & 15.09 \\
\hline 0.1 & 0.67 & 27.56 & 13.23 & 24.05 & 9.82 & 36.4 & 15.83 & 46.71 & 15.16 & 43.56 & 12.56 & 32.47 & 10.44 \\
\hline 0.2 & 0.33 & 21.98 & 18.91 & 19.03 & 14.56 & 33.88 & 25.07 & 48.8 & 22.30 & 48.27 & 20.45 & 25.68 & 11.01 \\
\hline 0.2 & 0.50 & 24.93 & 16.66 & 22.33 & 13.05 & 35.38 & 20.54 & 47.25 & 19.02 & 45.58 & 15.01 & 33.37 & 13.21 \\
\hline 0.2 & 0.67 & 26.99 & 16.16 & 22.99 & 10.75 & 36.09 & 16.33 & 46.1 & 16.56 & 43.33 & 12.16 & 32.36 & 10.92 \\
\hline 0.5 & 0.33 & 20.54 & 19.02 & 19.04 & 14.78 & 31.39 & 26.32 & 46.68 & 24.77 & 46.61 & 22.15 & 30.54 & 23.8 \\
\hline 0.5 & 0.50 & 22.81 & 17.06 & 20.30 & 13.12 & 33.88 & 24.22 & 46.41 & 20.21 & 44.91 & 18.38 & 31.41 & 16.83 \\
\hline 0.5 & 0.67 & 25.89 & 14.61 & 22.19 & 12.51 & 34.92 & 18.23 & 45.93 & 16.36 & 43.08 & 13.29 & 31.35 & 11.46 \\
\hline 0 & 1.00 & 45.35 & 14.29 & 41.40 & 11.23 & 26.76 & 6.55 & 23.62 & 4.51 & 42.06 & 9.93 & 30.7 & 7.66 \\
\hline
\end{tabular}

$\mathrm{X}$ is concentration of $\mathrm{NaCl}$ aqueous solution, $\mathrm{x}$ is the molar fraction of DMSO.

\begin{tabular}{|c|c|c|c|c|c|c|c|c|c|c|c|c|c|}
\hline \multicolumn{14}{|c|}{$\begin{array}{c}\text { TABLE-2 } \\
\text { REAL AND IMAGINARY PARTS OF THE EFFECTIVE PERMITTIVITY (DIELECTRIC CONSTANT) } \\
\text { FOR DMSO +NaCl IN WATER MIXTURES (AT 5.8 GHz) AT DIFFERENT TEMPERATURES }\end{array}$} \\
\hline \multirow{2}{*}{\multicolumn{2}{|c|}{$5.8 \mathrm{G}$}} & \multicolumn{2}{|c|}{$293 \mathrm{~K}$} & \multicolumn{2}{|c|}{$298 \mathrm{~K}$} & \multicolumn{2}{|c|}{$308 \mathrm{~K}$} & \multicolumn{2}{|c|}{$318 \mathrm{~K}$} & \multicolumn{2}{|c|}{$338 \mathrm{~K}$} & \multicolumn{2}{|c|}{$353 \mathrm{~K}$} \\
\hline & & $\varepsilon^{\prime}$ & $\varepsilon^{\prime \prime}$ & $\varepsilon^{\prime}$ & $\varepsilon^{\prime \prime}$ & $\varepsilon^{\prime}$ & $\varepsilon^{\prime \prime}$ & $\varepsilon^{\prime}$ & $\varepsilon^{\prime \prime}$ & $\varepsilon^{\prime}$ & $\varepsilon^{\prime \prime}$ & $\varepsilon^{\prime}$ & $\varepsilon^{\prime \prime}$ \\
\hline $\mathrm{X}(\mathrm{mol} / \mathrm{L})$ & x (DMSO) & \pm 3.5 & \pm 1.2 & \pm 3.5 & \pm 1.2 & \pm 3.4 & \pm 1.2 & \pm 3.3 & \pm 1.2 & \pm 3.5 & \pm 1.2 & \pm 3.2 & \pm 1.3 \\
\hline 0 & 0 & 78.99 & 10.7 & 77.23 & 9.15 & 73.77 & 6.49 & 70.65 & 4.88 & 65.81 & 3.59 & 61.52 & 2.53 \\
\hline 0.1 & 0.33 & 14.81 & 10.51 & 15.17 & 8.04 & 17.96 & 17.6 & 30.26 & 27.59 & 29.66 & 25.74 & 25.64 & 16.77 \\
\hline 0.1 & 0.50 & 15.99 & 10.34 & 15.49 & 7.54 & 18.96 & 16.82 & 29.3 & 25.40 & 30.67 & 24.47 & 21.45 & 15.13 \\
\hline 0.1 & 0.67 & 19.47 & 10.22 & 19.04 & 6.83 & 22.76 & 15.51 & 32.92 & 22.67 & 31.15 & 20.75 & 22.36 & 12.90 \\
\hline 0.2 & 0.33 & 14.84 & 10.24 & 14.62 & 7.21 & 17.2 & 16.73 & 29.41 & 26.51 & 27.81 & 26.91 & 17.1 & 10.56 \\
\hline 0.2 & 0.50 & 16.84 & 10.35 & 16.96 & 7.42 & 19.53 & 16.35 & 30.01 & 24.61 & 30.74 & 23.2 & 22.41 & 13.99 \\
\hline 0.2 & 0.67 & 18.6 & 10.46 & 18.12 & 6.85 & 22.11 & 15.68 & 31.03 & 23.28 & 30.93 & 20.71 & 22.51 & 12.43 \\
\hline 0.5 & 0.33 & 14.48 & 10.15 & 15.04 & 7.40 & 16.52 & 16.63 & 27.72 & 26.69 & 27.53 & 26.83 & 18.7 & 16.83 \\
\hline 0.5 & 0.50 & 15.67 & 9.98 & 15.91 & 7.07 & 17.21 & 16.60 & 29.15 & 25.05 & 28.16 & 24.34 & 19.83 & 14.59 \\
\hline 0.5 & 0.67 & 17.88 & 10.22 & 17.60 & 7.11 & 20.96 & 15.60 & 31.99 & 22.89 & 31.21 & 20.64 & 22.31 & 12.57 \\
\hline 0 & 1.00 & 45.35 & 14.29 & 41.40 & 11.23 & 26.76 & 6.50 & 23.62 & 4.51 & 42.06 & 9.93 & 30.7 & 7.66 \\
\hline
\end{tabular}

$\mathrm{X}$ is concentration of $\mathrm{NaCl}$ aqueous solution, $\mathrm{x}$ is the molar fraction of DMSO.

decreases with increasing temperature and it is probably due to an increase in relaxation time of solvent molecules as viscosity decreases with temperatures. This behaviour was typical for all temperatures and solvents. Dielectric properties were also determined to be solvent ratio dependent.

From Tables 1 and 2 it also can be seen that dielectric constant of $\mathrm{DMSO}+\mathrm{NaCl}$ aqueous solutions were also ratio dependent, with 1:2 ratios having the minimum values. The dielectric loss of all mixtures varied with frequency, temperature, solvent type and mix ratio. For DMSO, dielectric loss increased to a maximum around 0.33 (DMSO with water ratios is 1:2) but then decreasing as mix ratio (Figs. 1 and 2). In addition to having a maximum around 0.33 , the dielectric loss value at 2.45 and $5.8 \mathrm{MHz}$ were very similar, raising the possibility of a relatively smooth transition with no major changes in behaviour between these two frequencies. Dielectric loss also showed to be dependent on aqueous solution of $\mathrm{NaCl}$ concentration. Among the solvents investigated in this study, $0.5 \mathrm{~mol} / \mathrm{L} \mathrm{NaCl}$ aqueous solution had the highest values of $\varepsilon^{\prime \prime}$, indicating a good medium for high energy conversion into heat.

\section{Conclusion}

Dielectric properties of DMSO-NaCl aqueous solution dispersions were studied as function of concentration and

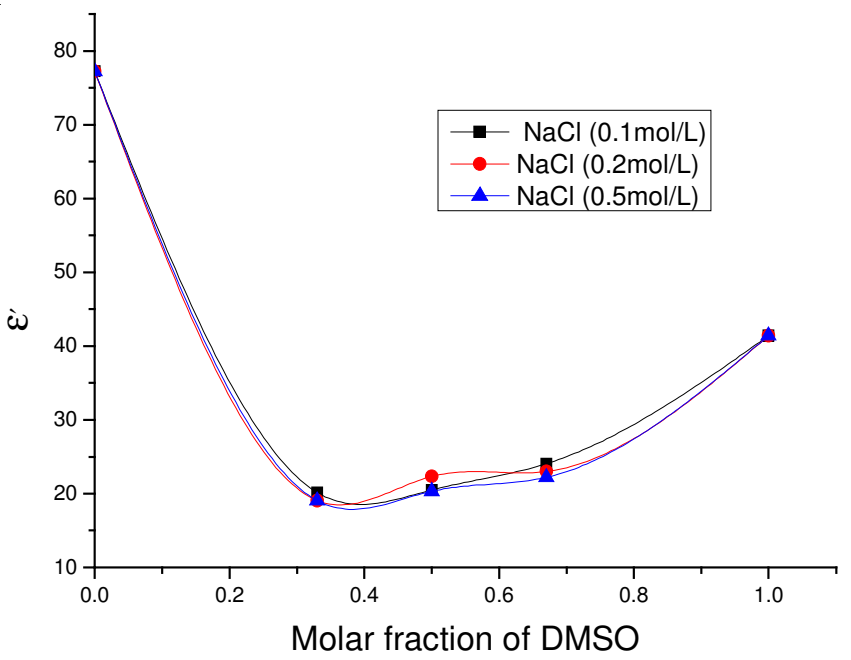

Fig. 1. Real parts of the effective permittivity of DMSO $+\mathrm{NaCl}(0.1-0.5$ $\mathrm{mol} / \mathrm{L}$ ) in water mixtures where $\mathrm{T}=298 \mathrm{~K}$ and $\mathrm{f}=2.45 \mathrm{GHz}$

temperature in the microwave frequency range 2.45 and 5.8 GHz. Results indicated that dielectric parameters were considerably influenced by concentration and temperature. Both dielectric constant and loss factor was significantly decreased with temperature. This study provides new information related 


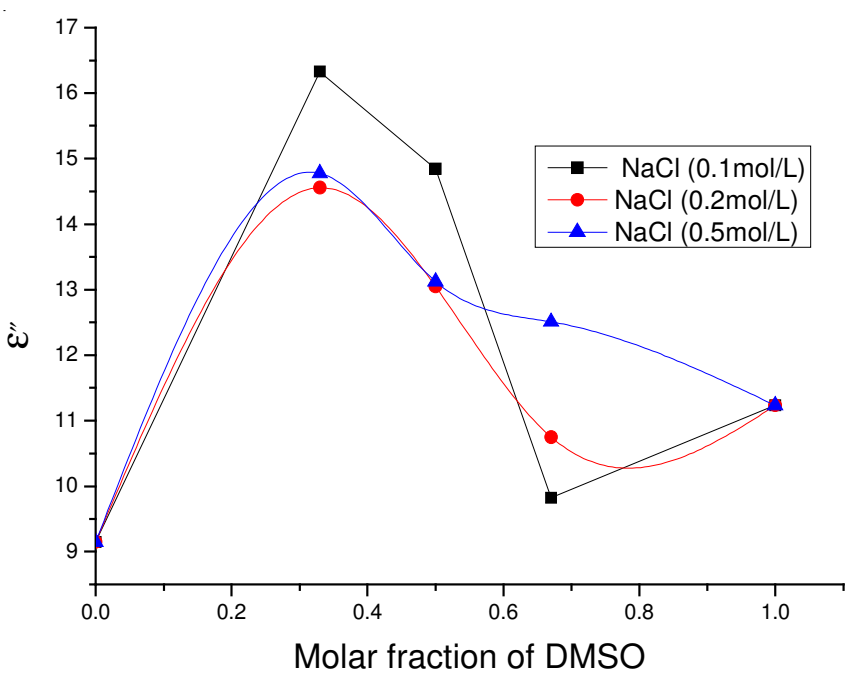

Fig. 2. Imaginary parts of the effective permittivity of DMSO $+\mathrm{NaCl}(0.1$ $0.5 \mathrm{~mol} / \mathrm{L}$ ) in water mixtures where $\mathrm{T}=298 \mathrm{~K}$ and $\mathrm{f}=2.45 \mathrm{GHz}$

to temperature and concentration dependence of DMSO-NaCl aqueous solution dispersions dielectric properties that may be useful in dielectric heating and product development appli- cations, however the effect of temperature on the dielectric loss of DMSO $\mathrm{NaCl}$ aqueous solution is still not completely elucidated and deserves further investigations.

\section{ACKNOWLEDGEMENTS}

This project was supported by the National Science Foundation of China under Grant No. 61102044 and No. 61001019.

\section{REFERENCES}

1. D. Martin and H.G. Hauthal, Dimethyl Sulfoxide, Wiley, New York (1975).

2. S.W. Jacob, E.E. Rosenbaum and D.C. Wood Dekker, Dimethyl Sulfoxide, New York, Vol. 1 (1971).

3. J.J. Lindberg and J. Pietila, Suomen Kemi, B35, 30 (1962).

4. Y. Doucet, F. Calmes-Perrault and M.T. Durand, C.R. Acad. Sci. Paris, 260, 1878 (1965)

5. A. Luzar, J. Mol. Liq., 46, 221 (1990).

6. E. Tommila and A. Pajunen, Suomen Kemi, B41, 172 (1968).

7. O.A. Karim and J.A. McCammon, J. Am. Chem. Soc., 108, 1726 (1986).

8. E. Guardia, R. Rey and J.A. Padro, J. Chem. Phys., 155, 187 (1991).

9. G. Sese, E. Guardia and J.A. Padro, J. Phys. Chem., 99, 12647 (1995).

10. M. Madhusoodanan and B.L. Tembe, J. Phys. Chem., 98, 7090 (1994).

11. G. Ciccotti, M. Ferrario, J.T. Hynes and R. Kapral, J. Chem. Phys., 93, 7137 (1990). 